\title{
ANALISIS UPAYA PENINGKATAN PELAYANAN KESEHATAN BAGI PASIEN GANGGUAN JIWA DI KOTA KOTAMOBAGU
}

\author{
ANALYSIS EFFORTS TO IMPROVE HEALTH SERVICES \\ PATIENTS MENTAL DISORDERS IN KOTAMOBAGU CITY
}

\author{
Sudirman $^{1 *}$, Sitti Rahma Soleman ${ }^{2}$ \\ 1*Program Studi Kesehatan Masyarakat, Fakultas Kesehatan, Institut Kesehatan dan Teknologi Graha \\ Medika, Jl. Mogolaing, Kotamobagu Barat, Kota Kotamobagu, Sulawesi Utara, Indonesia \\ ${ }^{2}$ Program Keperawatn, Fakultas Kesehatan, Institut Kesehatan dan Teknologi Graha Medika \\ Jl. Mogolaing, Kotamobagu Barat, Kota Kotamobagu, Sulawesi Utara, Indonesia \\ *email: sudirmandirman549@.com
}

\begin{abstract}
Mental health is a person's behavior that can be an indicator of or about the state of his mental health. Mental health, a major health problem in Indonesia. The prevalence of mental disorders in North Sulawesi Province 2016 was 4,179 and in 2019, 7,089 people experienced mental disorders, Kotamobagu City an area in North Sulawesi province which has contributed with a prevalence rate of 75\% from 2018 to 2020. study type of quantitative descriptive research, using an observational approach with a questionnaire tool. This research was conduct to improve the quality of mental health services in all Public Health Centers in Kotamobagu City. Held in April 2021, in all Public Health Center in Kotamobagu City (5 Public Health Center). The research population has two characters, 15 health workers and 109 people with mental disorders, a research sample of 15 people from mental health workers, and 45 people from the community with mental disorders. results of the study indicate that there is an unfavorable difference or gap between mental health services expected by the community with mental disorders and mental health services provided by health center health workers in Kotamobagu City, gap value (0.34) and $p$-value $=0.038<=0.05$. Significant gaps in mental health services in all Public Health Center in Kotamobagu City because the dimensions of Tangible, Reliability, Empathy health services have not been implemented optimally according to the expectations of the people with mental disorders. all Public Health Center in Kotamobagu City even exceeds what the community expects.
\end{abstract}

Keyword: Health Services, Mental Health Service, Mental Disordres

\begin{abstract}
Abstrak
Kesehatan jiwa merupakan perilaku seseorang yang dapat menjadi indikator terhadap atau tentang keadaan kesehatan jiwanya. Kesehatan jiwa merupakan masalah kesehatan utama di Indonesia. Prevalensi gangguan jiwa di Provinsi Sulawesi Utara sejak tahun 2016 sebanyak 4.179 orang hingga tahun 2019 tercatat sebanyak 7.089 orang yang mengalami gangguan jiwa. Kota Kotamobagu merupakan wilayah dari provinsi sulawesi utara yang memiliki kontribusi dengan laju prevalensi sebesar 75\% sejak 2018 hingga 2020. Penelitian ini merupakan jenis penelitian deskriptif kuantitatif, menggunakan pendekatan observational dengan alat bantu kuesioner. Penelitian ini dilakukan untuk meningkatkan kualitas pelayanan kesehatan jiwa di seluruh Puskesmas Kota Kotamobagu. Dilaksanakan pada bulan April 2021, di seluruh Puskesmas di Kota Kotamobagu (5 Puskesmas). Populasi penelitian terdiri dari dua karakter, petugas kesehatan sebanyak 15 orang dan masyarakat gangguan jiwa sebanyak 109 orang, sampel penelitian berjumlah 15 orang dari petugas kesehatan jiwa, dan 45 orang pihak masyarakat gangguan jiwa. Hasil penelitian menunjukkan bahwa terdapat perbedaan atau kesenjangan yang kurang baik antara pelayanan kesehatan jiwa yang diharapkan pihak masyarakat penderita gangguan jiwa dengan pelayanan kesehatan jiwa yang di berikan oleh petugas kesehatan Puskesmas di Kota Kotamobagu, dengan nilai kesenjangan sebesar $(0,34)$ dan signifikan $p$-value = 0,038. Kesenjangan yang signifikan dalam pelayanan kesehatan jiwa di seluruh Puskesmas di Kota
\end{abstract}


Kotamobagu dikarena oleh dimensi pelayanan kesehatan Tangible, Reliability, Empathy, belum terlaksana dengan maksimal sesuai harapan pihak masyarakat yang mengalami gangguan jiwa Dimensi Assurance menjadi aspek yang telah memenuhi harapan pihak masyarakat yang mengalami gangguan jiwa di seluruh Puskesmas di Kota Kotamobagu bahkan melebihi apa yang di harapan oleh masyarakat. Kata Kunci: pelayanan kesehatan, perawatan kesehatan jiwa; gangguan jiwa

\section{PENDAHULUAN}

Kesehatan jiwa merupakan perilaku seseorang yang dapat menjadi indikator terhadap atau tentang keadaan kesehatan jiwanya, Setiap orang dapat memiliki pandangan atau interpretasi yang berbeda tentang perilaku, di kebanyakan kasus, kesehatan jiwa adalah keadaan emosional, psikologis, dan, dan stabilitas emosi seseorang (Videbeck, 2019). Kesehatan jiwa merupakan masalah kesehatan utama di Indonesia. Data survei nasional tahun 1995 menyebutkan bahwa prevalensi gangguan jiwa pada anak dan remaja adalah 104/1000 dan untuk dewasa 140/1000. Sedangkan prevalensi psikosis 3/1000, demensia 3/1000, retardasi mental 5/1000, dan gangguan jiwa lainnya 5/1000. Survei terakhir tahun 2007 menyebutkan bahwa prevalensi nasional gangguan jiwa adalah $11,6 \%$ (116/1000), (DEPKES RI, 2012). Pelayanan kesehatan jiwa di Indonesia sebagian besar diberikan sebagai pelayanan berbasis rumah sakit. Sebuah strategi untuk transformasi sistem kesehatan jiwa awalnya didokumentasikan dalam Kebijakan Kesehatan Mental Nasional 2001.

Kesehatan jiwa merupakan masalah kesehatan utama di Indonesia. Berdasarkan data survei nasional, menyebutkan bahwa prevalensi gangguan jiwa pada anak dan remaja adalah 104/1000 dan 140/1000 pada orang dewasa. Sedangkan prevalensi psikosis 3/1000, demensia 3/1000, retardasi mental 5/1000, dan gangguan jiwa lainnya pada 5/1000 (Depkes 2009), Survei terakhir tahun 2007 menyebutkan prevalensi nasional gangguan jiwa adalah $11,6 \%$ (116/1000), (DEPKES RI, 2012).

Pelayanan kesehatan jiwa di Indonesia sebagian besar diberikan sebagai layanan berbasis rumah sakit. Pelayanan kesehatan jiwa telah diintegrasikan ke dalam pelayanan kesehatan umum di puskesmas dan jejaringnya, klinik pratama, praktisi umum dengan kompetensi untuk memberikan pelayanan kesehatan jiwa, perawatan di rumah dan fasilitas pelayanan di luar bidang kesehatan serta CBR fasilitas. Hingga tahun 1990, pelayanan kesehatan jiwa dilakukan melalui pengenalan spesialis psikiatri ke Puskesmas di beberapa provinsi. Pelayanan rujukan kesehatan jiwa disediakan di rumah sakit jiwa dan pelayanan kesehatan jiwa diintegrasikan ke pelayanan kesehatan rumah sakit umum, klinik pratama dan praktik spesialis kesehatan jiwa (Mahendradhata, et al., 2017).

Gangguan jiwa masih menjadi masalah kesehatan jiwa serius di Indonesia yang perlu mendapat perhatian lebih dari pemangku kebijakan kesehatan nasional. Meskipun masih belum menjadi program prioritas utama kebijakan kesehatan nasional, namun dari angka yang didapatkan dari beberapa riset nasional menunjukkan bahwa penderita gangguan jiwa di Indonesia masih banyak dan cenderung mengalami peningkatan. Berdasarkan hasil Riset Kesehatan Dasar (Riskesdas) tahun 2007 terdapat $0,46 \%$ dari total populasi Indonesia atau setara dengan 1.093.150 jiwa penduduk Indonesia berisiko tinggi mengalami skizofrenia (Lestari \& Wardhani, 2014).

Umumnya di Indonesia orang dengan gangguan jiwa (ODGJ) penanganannya dikenal sebagai pemasungan. Hal tersebut di anggap dapat membatasi perilaku ODGJ. Hal ini menyebabkan OGDJ sulit untuk dipulihkan. Keadaan tersebut menimbulkan stigmatisasi dalam masyarakat yang dapat meningkatkan hal buruk terhadap ODGJ. Orang dengan gangguan jiwa terhambat untuk mendapatkan penanganan dari pelayanan kesehatan dan ODGJ umumnya menjadi korban diskriminasi (Dewi, et al., 2019).

Provinsi Sulawesi Utara menjadi salah satu provinsi yang memiliki prevalensi gangguan jiwa sejak tahun 2016 sebanyak 4.179 orang hingga tahun 2019 tercatat sebanyak 7.089 orang yang mengalami gangguan jiwa, (Riskesdas, 2018). Kota Kotamobagu merupakan wilayah dari Provinsi Sulawesi Utara yang memiliki kontribusi dengan laju prevalensi sebesar $75 \%$ sejak 2018 hingga 2020. Jumlah gangguan jiwa tercatat sejak tahun 2018 sebanyak 27 orang hingga 2020 sebanyak 105 orang yang mengalami gangguan jiwa.

Observasi dan studi pendahuluan dilakukan pada tanggal 13-17 Maret tahun 2021 
di wilayah Kota Kotamobagu pada keluarga penderita ODGJ untuk mengetahui keadaan atau fakta sesungguhnya terkait masalah kesehatan jiwa di lapangan yang akan dikaji oleh peneliti. Berdasarkan hasil observasi kepada 3 informan berbeda, didapatkan informasi bahwa tata kelola layanan kesehatan mental masih belum memadai di wilayah Kota Kotamobagu, pertama disebabkan karena kurangnya fasilitas pendukung seperti SDM, dan sarana prasarana pengobatan, serta belum adanya tindakan penanganan psikologi secara serius dan pelayanan yang hanya terfokus pada pemberian obat. Penelitian ini dilakukan dengan tujuan untuk mengetahui dan menganalisis terkait pelayanan kesehatan jiwa di seluruh Puskesmas kota Kotamobagu yang tepat dengan harapan masyarakat dengan status ODGJ.

\section{METODE PENELITIAN}

Penelitian ini merupakan jenis penelitian kuantitatif dengan model deskriptif, menggunakan pendekatan observational analytic dengan desain studi ekologi atau korelasi dengan alat bantu kuesioner. Penelitian dilaksanakan di seluruh Puskesmas (5 Puskesmas) di Kota Kotamobagu, pada bulan Maret-Mei 2021. Variabel yang di teliti yaitu kualitas pelayanan kesehatan jiwa yang diselenggarakan pada Puskesmas di Kota Kotamobagu. Populasi penelitian terdiri atas 2 karakteristik yaitu petugas kesehatan jiwa yang berjumlah 15 orang dan pihak masyarakat dengan gangguan jiwa sebanyak 105 orang. Sampel dalam penelitian ini yaitu petugas kesehatan jiwa sebanyak 15 orang dan masyarakat dengan status gangguan jiwa sebanyak 45 orang. Sampel dipilih menggunakan teknik nonprobability sampling, pengambilan sampel dilakukan menggunakan metode accidental sampling. Data di analisis menggunakan analisis paired t-test untuk mengetahui tingkat signifikansi perbedaan antara pelayanan kesehatan yang diharapkan oleh pihak ODGJ dengan layanan kesehatan jiwa yang diberikan oleh petugas kesehatan pada Puskesmas di Kota Kotamobagu.

\section{HASIL DAN PEMBAHASAN}

\section{Pelayanan Kesehatan ODGJ pada Puskesmas Wilayah Kerja Kota Kotamobagu}

Berdasarkan hasil dari analisis data pada

Tabel 1. diketahui bahwa adanya perbedaan atau kesenjangan yang kurang baik antara pelayanan kesehatan jiwa yang diharapkan oleh masyarakat penderita gangguan jiwa dengan layanan kesehatan jiwa yang diberikan oleh petugas kesehatan jiwa di Kota Kotamobagu, hal tersebut dapat dilihat pada nilai kesenjangan yang dominan positif baik dari setip dimensi maupun pelayanan kesehatan jiwa secara keseluruhan $(0,34)$ secara statistik (uji paired $t$ test) menunjukkan nilai signifikan $p$-value $=$ 0,038 .

Berdasarkan hasil analisis data penelitian di ketahui bahwa pelayanan kesehatan jiwa yang di harapkan oleh pihak masyarakat yang menderita gangguan jiwa masih belum sesuai dengan apa yang di berikan oleh petugas kesehatan dalam penyediaan pelayanan kesehatan jiwa, hal tersebut terbukti dari nilai kesenjangan dalam dimensi pelayanan kesehatan sebagai tolak ukur yang bernilai positif, yaitu Tangible dalam pelayanan kesehatan jiwa bernilai positif sebesar 1,08 dengan nilai signifikan $p$-value $=0,009$, Reliability dalam pelayanan kesehatan jiwa bernilai positif sebesar 0,40 dengan nilai signifikan $\quad p$-value $=0,024, \quad$ Responsiviness dalam pelayanan kesehatan jiwa bernilai positif sebesar 0,60 dengan nilai signifikan $p$ value $=0,112$, dan, Empathy dalam pelayanan kesehatan jiwa bernilai positif sebesar 1,05 dengan nilai signifikan $p$-value $=0,05$. Namun hal yang berbeda di temukan pada dimensi pelayanan Assurance dalam pelayanan kesehatan jiwa bahwa dimensi ini memiliki nilai negatif sebesar $-1,41$ dengan nilai signifikan $p$-value $=0,05$.

Kualitas pelayanan kesehatan jiwa yang belum sesuai dengan yang di harapkan oleh pihak masyarakat yang memiliki gangguan jiwa khususnya pada dimensi pelayanan kesehatan Tangible, Reliability, Responsiviness, Empathy karena besarnya harapan pihak masyarakat yang menderita gangguan jiwa untuk mendapatkan kesembuhan dan di beri pelayanan yang maksimal.

Menurut Paramanik dalam hasil penelitiannya menguraikan bahwa kualitas suatu pelayanan kesehatan menjadi tidak memuaskan disebabkan oleh preferensi dari pasien terhadap dimensi pelayanan memiliki perbedaan dengan petugas kesehatan serta kurangnya informasi dan pengetahuan terhadap perkembangan pelayanan dan perawatan yang modern (Paramanik, 2016). 
99 Ikesma: Jurnal Ilmu Kesehatan Masyarakat, Vol. 17, No. 2 September 2021, 96-102

Tabel 1. Distribusi Perbedaan Pelayanan Kesehatan Jiwa Layanan yang Diberikan oleh Petugas Kesehatan Jiwa di Kota Kotamobagu.

\begin{tabular}{|c|c|c|c|c|c|c|c|c|c|}
\hline \multirow{2}{*}{$\begin{array}{c}\text { Dimensi } \\
\text { Variabel } \\
\text { Pelayanan } \\
\text { Kesehatan } \\
\text { Jiwa }\end{array}$} & \multirow[b]{2}{*}{ Pernyataan } & \multicolumn{4}{|c|}{$\begin{array}{c}\text { Kualitas Dimensi Layanan Kesehatan } \\
\text { Jiwa }\end{array}$} & \multicolumn{4}{|c|}{ Kualitas Layanan Kesehatan Jiwa } \\
\hline & & $\begin{array}{l}\text { Harapan } \\
\text { ODGJ }\end{array}$ & $\begin{array}{l}\text { Layanan } \\
\text { ODGJ }\end{array}$ & $\begin{array}{l}\text { Kesen- } \\
\text { jangan }\end{array}$ & $p$-value & $\begin{array}{l}\text { Harapan } \\
\text { ODGJ }\end{array}$ & $\begin{array}{l}\text { Layanan } \\
\text { ODGJ }\end{array}$ & $\begin{array}{l}\text { Kesen- } \\
\text { jangan }\end{array}$ & $p$-value \\
\hline \multirow{5}{*}{ Tangible } & $\mathrm{P} 1$ & \multirow{5}{*}{4,54} & \multirow{5}{*}{3,46} & \multirow{5}{*}{1,08} & \multirow{5}{*}{0,009} & & & & \\
\hline & $\mathrm{P} 2$ & & & & & & & & \\
\hline & P3 & & & & & & & & \\
\hline & $\mathrm{P} 4$ & & & & & & & & \\
\hline & P5 & & & & & & & & \\
\hline \multirow{4}{*}{ Reliability } & $\mathrm{P} 1$ & \multirow{4}{*}{4,54} & \multirow{4}{*}{4,14} & \multirow{4}{*}{0,40} & \multirow{4}{*}{0,024} & & & & \\
\hline & $\mathrm{P} 2$ & & & & & & & & \\
\hline & $\mathrm{P} 3$ & & & & & & & & \\
\hline & $\mathrm{P} 4$ & & & & & & & & \\
\hline \multirow{4}{*}{$\begin{array}{l}\text { Responsivi- } \\
\quad \text { ness }\end{array}$} & P1 & \multirow{4}{*}{4,00} & \multirow{4}{*}{3,40} & \multirow{4}{*}{0,60} & \multirow{4}{*}{0,112} & 3,62 & 3,96 & 0,34 & 0,038 \\
\hline & $\mathrm{P} 2$ & & & & & 3,62 & 3,90 & 0,34 & \\
\hline & P3 & & & & & & & & \\
\hline & P4 & & & & & & & & \\
\hline \multirow{3}{*}{ Assurance } & $\mathrm{P} 1$ & \multirow{3}{*}{2,89} & \multirow{3}{*}{4,30} & \multirow{3}{*}{$-1,41$} & \multirow{3}{*}{0.030} & & & & \\
\hline & $\mathrm{P} 2$ & & & & & & & & \\
\hline & $\mathrm{P} 3$ & & & & & & & & \\
\hline \multirow{4}{*}{ Empathy } & $\mathrm{P} 1$ & \multirow{4}{*}{3,84} & \multirow{4}{*}{2,80} & \multirow{4}{*}{1,05} & \multirow{4}{*}{0,250} & & & & \\
\hline & $\mathrm{P} 2$ & & & & & & & & \\
\hline & $\mathrm{P} 3$ & & & & & & & & \\
\hline & P4 & & & & & & & & \\
\hline
\end{tabular}

Dalam dimensi pelayanan Tangible di ketahui bahwa belum sesuai dengan yang diharapkan oleh pihak masyarakat yang mengalami gangguan jiwa hal tersebut terlihat dari keinginan pihak masyarakat yang mengalami gangguan jiwa yang masih membutuhkan fasilitas perawatan bagi orang yang memiliki gejala gangguan jiwa (Pos Pembinaan Terpadu Psikiatri) sebagai wadah pembinaan bagi orang dengan gejala dan telah mengalami gangguan jiwa serta ketersediaan waktu pelayanan jiwa dengan SOP yang jelas, baik kunjungan ke rumah penderita maupun layanan di puskesmas termasuk rujukan.

Fasilitas Pos Pembinaan Terpadu Psikiatri sangat dibutuhkan untuk membantu keluarga melakukan perawatan bagi orang yang mengalami gangguan jiwa. Menurut hasil penelitian Rekoningsih (2016), bahwa sebagian besar keluarga pasien merasa sangat kesulitan mengelola dan mengatasi secara mandiri keluarga yang mengalami gangguan jiwa sehingga berdampak pada emosional yang tidak stabil dan kelelahan secara fisik, dukungan secara eksternal sangat di perlukan dan akan sangat membantu keluarga dalam perawatan pasien dengan gangguan jiwa, (Reknoningsih, et al., 2016).

Efektifitas manajemen penatalaksanaan pelayanan kesehatan belum dapat tercapai karena minimnya dukungan sumber daya yang memadai, untuk mengelola dan menyediakan pelayanan yang terstandar. Regulasi yang masih kurang terhadap peningkatan kualitas sumber daya sehingga berdampak pada rendahnya wujud layanan kesehatan yang dapat disediakan oleh petugas kesehatan dalam memberikan pelayanan kesehatan jiwa serta kurangnya pengetahuan dan konsep perawatan yang terintegrasi terhadap petugas kesehatan jiwa pada tingkat manajemen dan pelaksana (Massie, 2016).

Reliability dalam pelayanan kesehatan jiwa menjadi bagian dari dimensi pelayanan kesehatan jiwa yang menjadi aspek yang belum sesuai harapan pihak masyarakat yang 
menderita gangguan jiwa hal tersebut diketahui dari kurangnya petugas kesehatan jiwa yang dapat memberikan layanan gangguan jiwa, baik karena kurangnya petugas ahli jiwa atau dokter jiwa maupun dari fasilitas yang mendukung penyelenggaraan pelayanan perawatan kesehatan untuk mengatasi gejala bagi masyarakat yang menderita gangguan jiwa, sehingga kinerja pelayanan kesehatan jiwa yang ditunjukkan kurang handal.

Penempatan sumber daya yang tidak sesuai antara keahlian dengan fungsi yang seharusnya dilakukan dapat menyebabkan kinerja dalam pelayanan kesehatan yang diberikan menjadi kurang maksimal sehingga tidak dapat diandalkan, serta rendahnya kesadaran dan soft skill petugas kesehatan untuk memaksimalkan fasilitas medis, fasilitas pendukung dan anggaran yang telah diberikan pemerintah daerah (Rosie, et al., 2017).

Albertha dkk mengungkapkan dari hasil penelitiannya yang telah di lakukan pada tahun 2019 bahwa di Puskesmas belum mendapatkan dukungan untuk melaksanakan kegiatan peningkatan kualitas tenaga kesehatannya, serta Puskesmas tidak melibatkan jaringannya sebagai mitra yang dapat memberikan dukungan pelaksanaan program perawatan dalam layanan kesehatan jiwa, hal tersebut terjadi karena kesehatan jiwa belum menjadi salah satu program prioritas hampir bagi semua Puskesmas, (Albertha, et al., 2020).

Pembentukan tim kader kesehatan jiwa merupakan hal yang sangat penting dalam menyelenggarakan pelayanan kesehatan jiwa di pelayanan kesehatan primer, karena sangat membantu para profesional kesehatan, serta pelatihan rutin bagi kader yang sudah terbentuk terkait penatalaksanaan kesehatan jiwa menjadi hal yang sangat penting, (Kurniawan \& Sulistyarini, 2016)

Pemenuhan empathy dalam penyelenggaraan pelayanan perawatan bagi pihak masyarakat yang mengalami gangguan jiwa belum maksimal dan belum terpenuhi sesuai dengan apa yang di harapkan oleh pasien tersebut, hal ini terbukti dari masih kurangnya edukasi dan layanan konseling terkait penanganan gejala kejiwaan bagi pihak pengasuh, dan belum adanya pelatihan yang diberikan bagi pasien gangguan jiwa sebagai bentuk rehabilitatif.

Hal tersebut didukung oleh penelitian yang dilakukan Kurniawan dan Sulistyarini tahun 2016, dalam penelitiannya mengungkapkan bahwa sesungguhnya keluarga pasien sangat membutuhkan informasi terkait penanganan anggota keluarganya yang menderita gangguan jiwa serta belum adanya kunjungan petugas kesehatan khususnya dari Puskesmas setempat yang melakukan kunjungan dan observasi mengenai keadaan kejiwaan masyarakat, (Kurniawan \& Sulistyarini, 2016).

Menurut hasil penelitian Dali pada tahun 2019 di ketahui bahwa rendahnya intensitas pelatihan terkait kesehatan jiwa menyebabkan program pelayanan kesehatan jiwa pada setiap puskesmas menjadi kurang optimal di kabupaten Minahasa, (Dali, et al., 2019). Pemanfaatan layanan kesehatan jiwa di puskesmas cenderung kurang karena obat-obatan untuk penyakit kesehatan jiwa seperti Skizofernia yang tidak tersedia sehingga keluarga terkendala untuk mendapatkan obat untuk penderita gangguan jiwa, (Rahayuni, et al., 2017).

Orang yang mengalami gangguan jiwa dalam masyarakat kurang mendapatkan perhatian dalam diagnosis dan pengobatan yang tepat, secara umum penderita gangguan jiwa adalah orang yang normal namun psikologis yang dimiliki membutuhkan pertolongan medis yang tepat, pelayanan perawatan kesehatan jiwa pada masyarakat yang tidak menjadi prioritas menyebabkan mendapatkan perhatian yang minim dan anggaran yang berjumlah kecil, (Muhammad Ali, 2017)

Hal berbeda yang di temukan pada dimensi responsiveness dalam pelayanan kesehatan jiwa bahwa tidak terpenuhinya harapan masyarakat dalam layanan kesehatan jiwa tidak memiliki makna atau signifikansi yang kuat, namun masyarakat tetap mengharapkan adanya petugas kesehatan jiwa membentuk manager kasus yang melakukan komunikasi kepada masyarakat guna mengumpulkan informasi terkait masalah kesehatan jiwa. Demikian pula pada dimensi assurance dalam pelayanan kesehatan jiwa dimensi tersebut telah melebihi harapan pihak masyarakat yang menderita gangguan jiwa dengan signifikansi atau kemaknaan yang berarti, hal itu terbukti bahwa masyarakat merasa petugas kesehatan telah menjaga agar tidak terjadi tindakan diskriminasi dan stigma pada orang yang mengalami gangguan jiwa di tengah masyarakat, (Muhammad Ali, 2017).

Beragamnya cara yang dilakukan dalam pemberian pelayanan kesehatan bagi masyarakat yang berdampak terhadap keberagaman kualitas layanan kesehatan, 
namun secara keseluruhan pasien menilai pelayanan secara fungsional, dan Assurance dalam pelayanan kesehatan selalu menjadi prioritas karena elemen tersebut dipandang sangat penting oleh petugas kesehatan dan diharapkan masyarakat serta dimensi responsiveness dianggap sebagai hal yang penting bagi masyarakat (Al-Neyadi, et al., 2016).

Kesehatan jiwa seseorang sangat dipengaruhi oleh baik buruknya gaya hidup seseorang, gaya hidup yang kurang biak akan berdampak terhadap semakin beratnya gangguan jiwa atau mental yang akan di alami oleh seseorang, promosi kesehatan terkait gangguan jiwa harus lebih ditingkatkan baik dalam kuantitas dan cakupan sampai ke pelosok pedesaan. Promosi tentang gangguan jiwa dan peran aktif pelayanan kesehatan primer mengajak para masyarakat agar melakukan gaya hidup sehat, (Wardhani \& Paramita, 2016).

\section{KESIMPULAN DAN SARAN}

\section{Kesimpulan}

Masih terdapat perbedaan atau kesenjangan yang signifikan antara pelayanan yang diharapkan oleh masyarakat penderita gangguan jiwa dengan pelayanan kesehatan jiwa yang diberikan oleh petugas kesehatan jiwa di seluruh Puskesmas di Kota Kotamobagu. Pelayanan kesehatan jiwa setingkat Puskesmas di Kota Kotamobagu masih jauh dari harapan pihak masyarakat yang mengalami gangguan jiwa.

Dimensi Tangible, Reliability, Empathy, menjadi dimensi yang belum terlaksana dengan maksimal sesuai harapan pihak masyarakat yang mengalami gangguan jiwa dalam penyelenggaraan pelayanan kesehatan jiwa pada Puskesmas di Kota Kotamobagu. Dimensi Assurance menjadi aspek yang telah memenuhi harapan pihak masyarakat yang mengalami gangguan jiwa di pada Puskesmas di Kota Kotamobagu bahkan melebihi apa yang di harapan oleh masyarakat.

\section{Saran}

Petugas Puskesmas dapat melakukan promosi kesehatan dalam bentuk komunikasi dan edukasi kelompok kepada masyarakat terkait penatalaksanaan gangguan jiwa untuk mencegah terjadinya gangguan jiwa dan mengatasi gangguan jiwa yang terjadi pada masyarakat Kota Kotamobagu.

Membentuk kerja sama lintas sektor antara Dinas Sosial dan Dinas Kesehatan baik pada tingkatan kota maupun provinsi untuk membangun Pos Pelayanan Terpadu Psikiatri sebagai wadah pembinaan bagi masyarakat yang mengalami gangguan jiwa atau memiliki gejala gangguan jiwa, yang di lengkapi dengan dokter jiwa dan perawat psikiatri yang dapat melakukan layanan caregiver bagi masyarakat dengan gangguan jiwa yang membutuhkan pendampingan perawat jiwa.

\section{DAFTAR RUJUKAN}

1] Albertha $K$, Shaluhiyah $Z$ and Musthofa $S B$ (2020) Description of Mental Health Activities in Community Health Center Semarang City. Jurnal Kesehatan Masyarakat 8(No. 3): 440-447.

2] Al-Neyadi HS, Abdallah $S$ and Malik $M$ (2016) Measuring Patient'S Satisfaction of Healthcare Service in the UEA Hospital, Using SERVQUAL. International Journal of Helathcare management 2(No. 4): 1-11. https://doi.org/10.1080/20479700.2016.126 6804.

3] Dali FI, Ottay RI and Palandeng HM (2019) Kajian program kesehatan jiwa masyarakat di puskesmas Kabupaten Minahasa. Jurnal Kedokteran Komunitas dan Tropik 7(No. 2): 299-302.

4] DEPKES RI (2012) Profil Kesehatan Indonesia. [Online] Available at: https://pusdatin.kemkes.go.id/resources/do wnload/pusdatin/profil-kesehatanindonesia/profil-kesehatan-indonesia2012.pdf.

5] Dewi EI, Wuryaningsih EW and Susanto T (2019) Stigma Against People with Severe Mental Disorder (PSMD) with Confinement "Pemasungan". NurseLine Journal (NLJ) 4(No. $\quad$ 2): $131-138$. https://doi.org/10.19184/nlj.v4i2.13821.

6] Kurniawan Y and Sulistyarini I (2016) Komunitas SEHATI (Sehat Jiwa dan Hati) Sebagai Intervensi Kesehatan Mental Berbasis Masyarakat. INSAN; Jurnal Psikologi dan Kesehatan Mental 1(No. 2): 112-124.

https://doi.org/10.20473/jpkm.V1I22016.11 2-124. 
7] Lestari W and Wardhani YF (2014) Stigma and Management on People with Severe Mental Disorders with "Pasung" (Physical restraint). Buletin Penelitian Sistem Kesehatan: 157-168.

8] Mahendradhata Y. et al. (2017) The Republic of Indonesia Health System Review. Health System in Transition: 1-3.

9] Massie RGA (2016) The Assesment of Integrity on HIV/AIDS Prevention Program in Manado City. Buletin Penelitian Sistem kesehatan 19(No. 3): 1-9.

10] Muhammad Ali (2017) How Patients Perceive Helathcare Services, A Case of Ayub Teaching Hospital, AbbottabadPakistan. International Jurnal of Healthcare Management 11(No. 1): 1-9. https://doi.org/10.1080/20479700.2017.130 4324.

11] Paramanik A (2016) Patients Perception of Service Quality of Health Care Services in India. Health Management Research 18(No. 2): 205-217. https://doi.org/10.1177/0972063416637695.

12] Rahayuni IG. et al. (2017) Pemanfaatan Pelayanan Kesehatan Jiwa Di Puskesmas
Oleh Keluarga Penderita Skizofrenia. JRKN

1 No.

1):

75-80.

https://doi.org/10.37294/jrkn.v1i1.33.

13] Reknoningsih W, Daulima NHC and Putri YSE (2016) Pengalaman Keluarga Dalam Merawat Pasien Pasca Pasung. Jurnal Keperawatan Indonesia 18(No. 3): 171-180. https://doi.org/10.7454/jki.v18i3.421.

14] Riskesdas (2018) Laporan Provinsi Sulawesi Utara, Jakarta: Lembaga Penerbit Badan Penelitian dan Pengembangan Kesehatan.

15] Rosie Fitria and Widianti (2017) Kinerja Pegawai Puskesmas Dalam pelayanan Kesehatan di kecamatan Sangatta Selatan kabupaten Kutai Timur. e-Jurnal Ilmu Pemerintahan 6(No. 1): 165-198.

16] Videbeck SL (2019) Psychiatric-Mental Health Nursing. 8 ed. New York: Wolters Kluwer.

17] Wardhani YF and Paramita A (2016) Mental Health Services Disability and Life Style of Indonesian. Buletin Penelitian Sistem Kesehatan 19(No. 1): 99-107. https://doi.org/10.22435/hsr.v19i1.4994.99107. 